\title{
Organisational consequences of asymmetries in task dependence: the moderating role of $\mathrm{HR}$ practices
}

\author{
Simon B. De Jong, University of East Anglia, Norwich Business School \\ Florian Kunze, University of Konstanz, Chair for Organisational Studies \\ Heike Bruch, University of St. Gallen, Institute for Leadership and HRM \\ Human Resource Management Journal, Vol 27, no 1, 2017, pages 75-93
}

\begin{abstract}
This study integrates recent advances in interdependence theory with the literature on commitment-based HR practices. New research on interdependence theory suggests that differences, or asymmetries, in task dependence among organisational members can cause interests to diverge. Prior research has shown that this can negatively affect interpersonal relations, individual outcomes and team processes. However, these insights gained on the dyadic, individual and team levels of analysis have not yet been explored at the organisational level and, until now, no research had yet connected these advances in interdependence theory to the field of HRM research. Hence, the current study investigates (a) whether asymmetries in task dependence do (or do not) matter at the organisational level and affect organisational effectiveness, (b) why this relationship may work by assessing a key mediator, namely, trust climate and (c) if and how these relationships can be altered by commitment-based HR practices. Our moderated-mediation model was tested and fully supported by a multi-source data set of 8,390 employees from 67 organisations.
\end{abstract}

Contact: Prof. Simon B. De Jong, University of East Anglia, Norwich Business School, Norwich NR4 7TJ, UK. Email: s.de.jong@uea.ac.uk

Keywords: asymmetries in task dependence; trust climate; organisational effectiveness; commitment-based HR practices; interdependence theory; power

\section{INTRODUCTION}

$\square$ t has long been argued that one of the most crucial organisational characteristics is the structure and overall design of organisations (Thompson, 1967), because the interdependencies created by tasks and jobs across an organisation must align in order to create positive organisational processes and outcomes (e.g. Galbraith, 2014). One of the key theories that guide both practice and research on this issue is interdependence theory (e.g. Thibaut and Kelley, 1959; Van der Vegt et al., 2010). This theory deals with the phenomenon that organisational members are, to various extents, dependent on each other (Lewin, 1948), and it explains how processes and outcomes can become either positive or negative because of the con- or divergence of interests. Empirical findings demonstrate that interdependence can significantly influence intra-organisational processes, such as helping (Wageman and Baker, 1997), trust (Alge et al., 2003) and team effectiveness (Saavedra et al., 1993).

However, recently it has become apparent that most studies on interdependence theory have overlooked the possibility that differences, or asymmetries, in task dependence can also exist between organisational members (De Jong et al., 2007) and these could affect processes and outcomes in organisations as a whole. At the organisational level, these asymmetries in task dependence can be conceptualised as the degree to which there are differences across the organisation regarding the extent to which employees depend on others 
(Thibaut and Kelley, 1959). Traditionally, research has focused only on average task dependence, defined as the mean level at which employees depend on others ( $c f$. Nadler and Thusman, 1997; Galbraith, 2014). Acknowledging asymmetries is important, however, because organisational members who depend on colleagues for completing their tasks are vulnerable to abuses of power committed by asymmetrically less task-dependent members (e.g. Emerson, 1962; Fiske and Berdahl, 2007). These latter employees may attempt to exploit their advantage by withholding resources or setting extra demands when dealing with others. Recent studies have shown that asymmetries in task dependence can also be detrimental to helping behaviour and trusting work relationships (De Jong et al., 2007), individual job satisfaction and commitment (De Jong, 2014), and team learning and performance (Van der Vegt et al., 2010). Based on these dyadic-, individual- and team-level findings, it seems possible that asymmetries in task dependence might even affect organisational processes and effectiveness. ${ }^{1}$ However, these advances have not yet been examined at the organisational level nor connected to the HRM literature. Hence, the main goal of this study is to be the first to bring these new insights to a new level of analysis by investigating whether asymmetries in task dependence within organisations can have organisational-level effects.

Second, there is currently little insight into the theoretical mechanism through which asymmetrical task dependence can affect organisational effectiveness. Yet good insight into mechanisms and processes is important for scientific research and practical interventions alike (Sanders et al., 2014). Therefore, our second goal is to investigate the mechanism for why this organisational-level relationship might work. We draw on the literature on trust (e.g. Rousseau et al., 1998) and intra-organisational trust climate (Huff and Kelley, 2003) to argue that a key mediating process is the climate of intra-organisational trust. Following Huff and Kelley (2003: 82), we define the intra-organisational trust climate as the 'positive expectations that individuals have about the intent and behaviours of multiple organisational members based on organisational roles, relationships, experiences, and interdependencies.' We argue that when organisations have higher levels of asymmetries, they also tend to have more inequalities and differences that increase the possibilities for power abuse and the violation or exploitation of trust (Rousseau et al., 1998). Consequently, we expect trust climate to be a key mediator between asymmetries and organisational effectiveness.

Third, the above relationships are not as straightforward as it might appear at first glance, as the literature on power (Emerson, 1962; Keltner et al., 2003; Fiske and Berdahl, 2007) indicates that the advantages bestowed by asymmetries are sometimes abused for personal benefit, whereas under other circumstances, it can be used for the greater good. It is thus unclear whether positive or negative effects will arise at the organisational level. Although no research has yet investigated this issue, by drawing on interdependence theory (Thibaut and Kelley, 1959), it can be argued that asymmetrical task dependence is less likely to be abused when overarching and collective goals align different idiosyncratic interests (cf. Bunderson and Reagans, 2011). The HR literature suggests that divergent interests can be managed by selecting those HR practices that best fit the key characteristics of each organisation (Delery and Doty, 1996). Scholars have argued that there are two main types of HR practices, namely commitment-based and transactional-based HR practices (Monks et al., 2013). In short, transaction-based practices create a more monetary, short-term, individualistic and competitive orientation among organisational members. In contrast, commitment-based HR practices strive to build relational, long-term, collective and cooperation-oriented exchange relationships (Collins and Smith, 2006). To manage divergent interests, the overarching and collective goals created by commitment-based HR practices 
seem particularly suited, and we therefore focus on those practices for this first study into the organisational-level effects of asymmetries. We will theorise that these practices might turn potentially negative effects into positives ones, because the powerful will share their resources when higher collective performance is in their own interest (Bunderson and Reagans, 2011). Consequently, our third goal for this paper is to investigate how organisations might manage organisational-level asymmetries, and we therefore assess whether commitment-based HR practices can act as a moderator and turn potential negative effects into positive ones.

In doing so, this study aims to advance both practical and scientific knowledge. Practically, this study can be used for evidence-based interventions (Rousseau and Barends, 2011), as it provides practitioners with the first empirical evidence regarding the organisational-level effects of the newly discovered asymmetries in task dependence. Scientifically, our investigation also contributes to research on asymmetries in task dependence by (a) supporting (or refuting) current theorising by bringing the investigation to a new level of analysis, namely, the organisational level, (b) expanding current knowledge by investigating a new theoretical mechanism, namely, the mediating effect of trust climate and (c) assessing for the first time whether these asymmetries can be managed by certain HR practices. By doing so, we respond to recent calls in the HRM literature for more cross-disciplinary work and for better connections between the HRM and the OB literatures (Huselid and Becker, 2011), in particular regarding HRM and trust (Searle and Dietz, 2012). As Figure 1 shows, our theory and analyses are at the organisational level; some variables were directly measured at the organisational level, while others were aggregated.

\section{THEORY DEVELOPMENT AND HYPOTHESES}

\section{The dual-sided effects of asymmetries on trust climate}

Drawing from interdependence theory (Thibaut and Kelley, 1959) and power-dependence theory (Emerson, 1962), and consistent with recent studies on asymmetries in task dependence at lower levels of analysis, such as the dyadic (De Jong et al., 2007) or team level (Van der Vegt et al., 2010), we view asymmetrical task dependence at the organisational level as having an imbalance in resource exchanges and power-dependence relationships between and among organisational members as these members perform their tasks (Van der Vegt et al., 2005).

FIGURE 1 Hypothesised organisational-level model

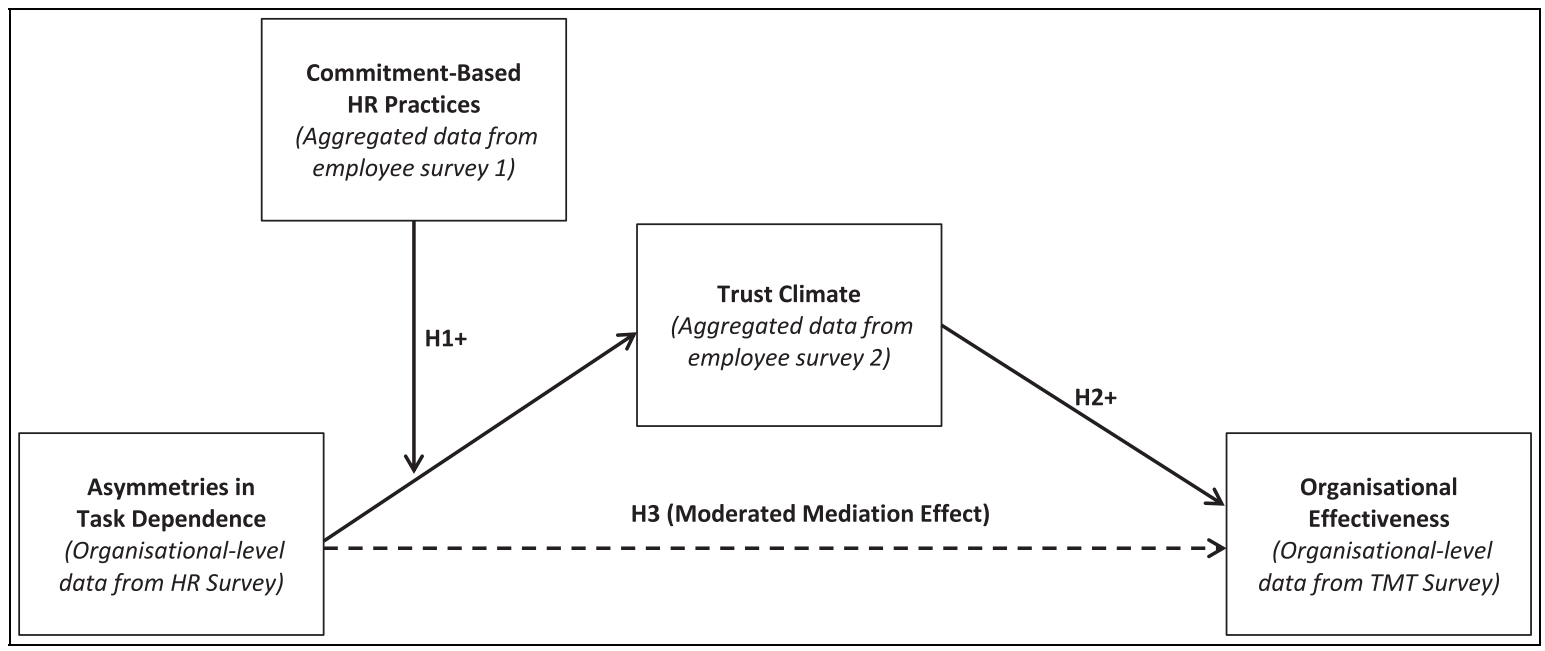


Therefore, organisations can be defined as having high asymmetries in task dependence when there are substantial differences between these organisational members in their reliance on others for the resources required to perform their work, such as information, materials and knowledge.

Interdependence theory and trust have been investigated in various studies (e.g. Balliet and Van Lange, 2013), but no study has investigated the organisational level of analysis. According to Rousseau et al. (1998), trust arises only when a vulnerability that could have been abused was not abused. We argue that the presence of many asymmetries in task dependence in an organisation indicates the existence of many vulnerabilities, because there are many differences in the possession of valued resources. Below, we will draw on new OB research conducted at the dyadic, individual and team levels of analysis and extrapolate their theory and findings to the organisational level to connect to the HRM literature (cf. Huselid and Becker, 2011).

Dyadic- and individual-level research suggests that asymmetries in task dependence can create problems in work relationships, as the interests of some employees may become pitted against the interests of others (Wieselquist et al., 1999). For example, individuals may compete for bonuses, prestigious projects or promotions. Naturally, such conflicting interests can sometimes be peacefully resolved; however, research has shown that this is difficult because increased asymmetries are associated with increased power differences (Emerson, 1962). Because research has also shown that being powerful diminishes one's desire to observe and interpret the behaviour of more dependent co-workers (Fiske et al., 2004), problems are likely to arise, as the less powerful members may simply be overlooked. Additionally, more powerful employees may feel little need to invest in work relationships with less powerful others, as the powerful can exit such relationships more easily (Giebels et al., 2000). When organisational members are abused or overlooked by others, trust is likely to suffer, and as De Jong et al. (2007) revealed, asymmetries can indeed undermine the relational trust between organisational members. Hence, prior research on the dyadic level of analysis indicates that the trust climate is likely to deteriorate with increasing levels of asymmetries between organisational members.

However, recent team-level research by Van der Vegt et al. (2010) has shown that asymmetrical task dependencies may actually increase intra-team learning and team performance when there is a focus on collective goals and outcomes. Although prior research has shown that asymmetries can be exploited (e.g. De Jong et al., 2007), there is thus also evidence that they can be used for the greater good, such as helping or learning (Van der Vegt et al., 2010; Bunderson and Reagans, 2011). Consequently, asymmetries - in and of themselves do not raise or lower trust; they merely increase the opportunity for trust to arise or deteriorate (cf. Rousseau et al., 1998), depending on whether the vulnerabilities are, or are not, abused. Therefore, possible moderators need to be studied.

\section{The moderation by commitment-based HR practices}

Interdependence theory (Thibaut and Kelley, 1959) suggests that asymmetries in task dependence are less likely to be abused, and are more likely to be put to good use, when employees are committed to collective and overarching goals and outcomes. Yet, there is currently no evidence on such potential moderators at the organisational level. Drawing from the HRM literature (e.g. Collins and Smith, 2006; Huselid and Becker, 2011) and current meta-analyses regarding HR practices and performance (e.g. Combs et al., 2006; Crook et al., 2011; Jiang et al., 2012), we argue that commitment-based HR practices can be that moderator. 
In the field of strategic HRM, two main types of HR practices are normally distinguished, namely, transaction-based and commitment-based HR practices (Collins and Smith, 2006). The former focuses on short-term and individual-focused exchange relationships, while the latter focuses on more reciprocal- and collective-focused long-term exchange relationships (cf. Monks et al., 2013). Research shows that commitment-based HR practices are more positive for organisational effectiveness than transaction-based HR practices (e.g. Toh et al., 2008). Commitment-based HR practices include, for example, compensation schemes that focus on collective indicators, development programmes that focus on long-term development and team building, and selection programmes that focus on good fit with the overall organisation instead of just a specific job (e.g. Collins and Smith, 2006). Hence, commitment-based HR practices can increase organisational effectiveness because they align idiosyncratic interests across the entire organisation (e.g. Combs et al., 2006; Jiang et al., 2012), and Collins and Smith (2006) found that commitment-based practices indeed positively relate to organisational effectiveness.

Theoretically, we argue that commitment-based HR practices are relevant for our study, as it would be counterproductive to work against colleagues when there are shared goals, because doing so would ultimately also affect one's own outcomes. Hence, linking back to the abovediscussed rational mechanisms that underlie asymmetries, the collective and long-term aspects of commitment-based HR practices can be expected to reduce power abuse and increase pro-social behaviour. Consequently, when asymmetries are combined with these HR practices, higher levels of trust should be created across the organisation. Empirical evidence supports this reasoning by demonstrating that common goals promote positive processes and cooperation across organisations (e.g. Tjosvold et al., 2005). Commitment-based HR practices also affect the above-discussed psychological mechanisms. Research has shown that those with power may 'forget' or overlook their dependent colleagues (Depret and Fiske, 1999). Commitment-based HR practices, such as team building, remind the powerful that their coworkers need them (and vice versa). In contrast, without commitment-based HR practices, the rational reasons for abusing power become stronger (e.g. to gain higher individual performance) and the powerful are then less often reminded of the needs of the powerless.

However, skeptics could argue that not all individuals will be directly affected by these processes, and they might thus wonder how organisational-level effects can arise. The concept of intra-organisational trust climate (Huff and Kelley, 2003) acknowledges that someone may lose trust while not being directly abused. For example, people can become increasingly mistrustful when their coworkers are the victims (or perpetrators) of power abuse. Conversely, seeing or hearing about the helping behaviour of colleagues can increase one's trust in coworkers ( $c f$. Rousseau et al., 1998). Further support comes from the literatures on affective events theory (Weiss and Cropanzano, 1996) and contagion processes (Barsade, 2002), which state that a (trust) climate can spread quickly across an organisation via both formal and informal information sharing among employees and role modelling (Gibson, 2004). Hence, we argue that more opportunities to add to (or detract from) a climate of trust exist in organisations with more asymmetrical task dependence than in organisations characterised by fewer differences among their employees. Given that commitment-based HR practices should impact both the rational and psychological power mechanisms associated with asymmetries in task dependence, our first hypothesis is:

Hypothesis 1: (H1): Asymmetrical task dependence negatively relates to trust climate when lower levels of commitment-based HR practices are provided, yet becomes increasingly more positive when higher levels are provided. 


\title{
Trust climate and organisational effectiveness
}

In their recent review on work climates, Kuenzi and Schminke (2009: 694) concluded that 'there is little doubt that climates matter and that they do so on numerous fronts.' We focus on trust climate as a mediator in our model, as that climate matches particularly well with the interdependence theory arguments which form the theoretical core of our study. Because we already argued in the text leading to Hypothesis 1 how asymmetries can affect trust climate, we will now discuss how trust climate can shape organisational effectiveness, to illustrate how the mediation works. Doing so is somewhat challenging as there is not much research on the organisational level. To illustrate, in 2012 Fulmer and Gelfand reviewed the trust literature and concluded that 'research predominately focus[ed] on trust at the individual level' (p. 1168). Yet some organisational-level research has been conducted and this indicates that trust climate can indeed operate as a mediator and ultimately affect organisational effectiveness (e.g. Huff and Kelley, 2003). More generally, prior research has also shown that trust increases variables which are important for organisational effectiveness, such as job satisfaction, intention to stay, cooperation (Montes and Irving, 2008) or knowledge sharing (McEvily et al., 2003). Thus, in conformance with the generally found effectiveness of work climates (Kuenzi and Schminke, 2009) and in line with Huff and Kelley (2003), we argue that it can be expected that high levels of internal trust will enable organisations to be more effective, compared to organisations which have low internal trust (Shockley-Zalabak et al., 2000). Consequently, our second hypothesis is as follows:

Hypothesis 2: (H2): Trust climate positively relates to organisational effectiveness.

\section{The moderated-mediating effect on organisational effectiveness}

Research in the field of strategic HRM indicates that the relationship between HR practices and organisational effectiveness tends to be indirect and work via social climates, for example, by increasing employee discretionary behaviours, such as knowledge sharing and organisational citizenship behaviours (Bowen and Ostroff, 2004; Woodrow and Guest, 2014) or by enhancing relational-coordination mechanisms (Gittell et al., 2010). Overall, prior research indicates that HR practices can affect trust (Searle and Dietz, 2012) and more specifically, in terms of commitment-based HR practices, Collins and Smith (2006) found that they affect organisational effectiveness by increasing trust (cf. Jiang et al., 2012). Combining all these insights, and referring back to our arguments for moderation ( $c f$. our text leading to Hypothesis 1$)$ and for an effect of trust on organisational effectiveness (cf. our text leading to Hypothesis 2 ), we expect that the interaction between commitment-based HR practices and asymmetries in task dependence will affect organisational effectiveness indirectly by shaping the trust climate across the entire organisation. Hence, our final hypothesis is as follows:

\begin{abstract}
Hypothesis 3: (H3): Commitment-based HR practices moderate the mediated relationship between asymmetrical task dependence, trust climate and organisational effectiveness, such that asymmetries indirectly and negatively relate to organisational effectiveness when lower levels of commitmentbased HR practices are provided; yet this indirect relationship becomes increasingly more positive when higher levels are provided.
\end{abstract}

\section{METHOD}

This study was part of a larger research programme and conducted in spring of 2010. We cooperated with a German HR-consulting organisation that contacted 89 German 
organisations and 67 of these provided information (a 75 per cent response). All organisational members were invited and 50.29 per cent responded to our surveys. The main industries were the service $(n=33)$ and production sector $(n=12)$. The remaining organisations came from the financial, healthcare, educational and hospitality sectors. On average, the organisations had 498 members $(\mathrm{SD}=832.04)$, average organisational tenure was 11.33 years $(\mathrm{SD}=11.75)$ and average age of organisational members was 37.75 years $(\mathrm{SD}=4.32)$.

To alleviate common method bias, we collected data from various sources (Podsakoff et al., 2012). General information and the asymmetry items were provided by a senior member of the organisation who was responsible for HR and other work design issues and because this was our main point of contact we could check if the questionnaire was fully understood by them. Commitment-based HR practices and trust climate were collected by two randomly-assigned, split-sample employee surveys, whereby 25 per cent of the employees were randomly selected for each survey. Organisational effectiveness was assessed by a fourth survey that was designed for the top management team (TMT), who were contacted through a different mail address compared to the HR professional. Thus, as Figure 1 shows, four unique sources were used. This data collection process resulted in 8,390 respondents for our study. Standardised procedures and survey formatting were used, and full confidentiality was assured. The surveys were translated into German, using a double-blind back-translation procedure. A standardised e-mail was sent to participants that described the study's purpose and provided a link to the web-based surveys.

\section{Measures}

Asymmetrical task dependence This measure was measured at the organisational level, by asking a senior professional with HR responsibilities. Using senior professionals as expert respondents is common in HRM research (e.g. Jiang et al., 2012; Sheehan et al., 2014; Bal and Dorenbosch, 2015; Bello-Pintado, 2015). Consistent with conceptualising asymmetrical task dependence as the imbalance in the resource exchanges and power-dependence relationships between and among organisational members as they perform their tasks (cf. Emerson, 1962; Fiske and Berdahl, 2007) and also drawing from recent studies (e.g. De Jong et al., 2007; Van der Vegt et al., 2010), we measured asymmetries in task dependence using the following four statements: (a) 'In our organisation, there are many differences between employees in their dependence on others for valuable information', (b) 'In our organisation, there are many differences between employees in their dependence on others for valuable materials', (c) 'In our organisation, there are many differences between employees in their dependence on others for valuable knowledge' and (d) 'In our organisation, there are many differences between employees in their dependence on others for valuable resources'. Respondents answered on a seven-point scale ( $1=$ totally disagree, $7=$ totally agree). Reliability was $\alpha=0.89$.

Commitment-based HR practices This variable was measured with the scale of Collins and Smith (2006), and we averaged employee responses for each organisation to create our organisational-level variable. Research on the 'HR Value Chain' has shown that HRM practices range from intended to actual practices and ultimately to perceived practices (e.g. Purcell et al., 2009). Therefore, we focused on employee perceptions as their perceptions of these practices are crucial in shaping how they think, feel, and behave (e.g. Bowen and Ostroff, 2004; Woodrow and Guest, 2014). We excluded one item (i.e. Item 7: 'Shares of stock are available to all core employees through stock purchase plans') as our focus on SMEs meant that most organisations did not have stock option plans. As such, our scale consisted of 15 items tapping three sub-dimensions (selection; incentives; training and development); example items were: 'Our selection system focuses on the potential of the candidate to learn and grow with the organisation'; 'Employee bonuses or incentive plans are based primarily on the performance of the organization'; 
'We provide training focused on team-building and teamwork skills training' (see Collins and Smith, 2006: 559$)$. We used a seven-point scale ( $1=$ totally disagree, $7=$ totally agree). Reliability was $\alpha=0.93$. The aggregation statistics supported aggregation $(F=7.63, p<0.001 ; \mathrm{ICC} 1=0.10$; $\mathrm{ICC}=0.87 ; \mathrm{Rwg}_{\text {(mean) }}=0.75$ ).

Organisational trust climate This variable was also constructed by aggregating the employee responses for each organisation, and we used the four items of Huff and Kelley (2003: 89). An example item was 'There is a very high level of trust throughout this organisation.' The four items were rated on a seven-point scale ( $1=$ totally disagree, $7=$ totally agree). Reliability was $\alpha=0.96$. The aggregation statistics supported aggregation $(F=8.22, p<0.001 ; \mathrm{ICC} 1=0.11 ; \mathrm{ICC} 2=0.88$; $\operatorname{Rwg}_{(\text {mean) }}=0.69$ ).

Organisational effectiveness We measured this variable at the organisational level by asking top management team members to individually respond to three items. Drawing from prior research (e.g. Wall et al., 2004), we asked the TMT to rate their own organisation's effectiveness relative to that of their competitors using a seven-point scale $(1=$ totally disagree, $7=$ totally agree). Reliability was $\alpha=0.76$. Specifically, we inquired regarding their organisation's 'overall performance', 'business efficiency' and 'increase in market share'. On average, the TMT's consisted of 4.47 members $(\mathrm{SD}=2.38)$ and on average 2.99 members responded $(\mathrm{SD}=1.90)$, producing a response rate of 67 per cent. The aggregation statistics supported aggregation $\left(F=2.26, p<0.001 ; \mathrm{ICC} 1=0.28 ; \mathrm{ICC} 2=0.56 ; \mathrm{Rwg}_{(\text {mean })}=0.87\right)$.

Control variables We controlled for organisational size, given that we had small- and mediumsized organisations and log transformed this variable to avoid skewness (e.g. Ragins et al., 2000). We also controlled for average age and average organisational tenure of employees as well as for the two key sectors (i.e. the service and production sectors) by adding dummy variables for each $(1=$ yes, $0=$ no). Last, following Van der Vegt et al. (2010: 353), we controlled for overall average task interdependence within the organisation, because 'past research suggests that the overall level of task interdependence might be associated with team processes and performance.' This was measured via the HR survey using the three Likert items reported in Van der Vegt, Van de Vliert, and Oosterhof (2003: 719). As noted in the Supporting Information, our results remained similar, regardless of the inclusion or exclusion of control variables.

\section{Discriminant and convergent validity}

To assess the discriminant and convergent validity of our variables, we followed recent organisation-level studies (e.g. Kunze et al., 2011) and performed an organisational-level confirmatory factor analysis. To have a better parameter-to-data ration in our relatively small sample, we used a partial disaggregation technique (Bagozzi and Heatherton, 1994; Williams and O'Boyle, 2008) for the HR practices by first creating the three main dimensions of this scale by summing the items (Collins and Smith, 2006). For the fit-indices we followed accepted standards (Bentler, 2007). The four-factor measurement model fit the data well $\left(\chi^{2}=102.095\right.$, $d f=71, p<0.01 ; \mathrm{SRMR}=0.073 ; \mathrm{CFI}=0.955 ; \mathrm{TLI}=0.942 ; \mathrm{AIC}=170.095)$. We also computed an alternative model wherein the two scales measured by the two groups of employees were collapsed into one factor. This three-factor model $(\Delta \chi 2=30.041, \Delta \mathrm{df}=3, p<0.001$; $\mathrm{SRMR}=0.102 ; \mathrm{CFI}=0.914 ; \mathrm{TLI}=0.895 ; \mathrm{AIC}=194.516)$ fit the data significantly worse than the four-factor model, indicating that, as expected, these two employee measures were unique. A two-factor model wherein the effectiveness items loaded on their own constructs, while the other three constructs were collapsed, also fit the data worse $(\Delta \chi 2=181.153, \Delta \mathrm{df}=5$, $p<0.001$; SRMR=0.180; CFI=0.697; TLI=0.637; $\mathrm{AIC}=341.248$ ). Finally, an alternative model 
wherein all items were collapsed into one latent construct fit the data worse $(\Delta \chi 2=224.957$, $\Delta \mathrm{df}=6, \quad p<0.001 ; \mathrm{SRMR}=0.209 ; \mathrm{CFI}=0.634 ; \mathrm{TLI}=0.568 ; \mathrm{AIC}=383.052)$. Therefore, we concluded that our theorised four-factor measurement model was the most appropriate, and all variables were both theoretically and empirically distinct.

\section{Analyses}

Our model focuses on the organisational level of analysis, and as Figure 1 shows, it is a firststage moderated-mediation model (Edwards and Lambert, 2007). For our analyses, we used the PROCESS (v2.11) procedures of Hayes (2013) in SPSS 21.

\section{RESULTS}

\section{Descriptive statistics}

The means, standard deviations and Pearson zero-order correlations are presented in Table 1. The correlation between asymmetries and trust climate was significant and negative $(r=-0.25$, $p<0.05)$ and trust climate positively related to commitment-based HR practices $(r=0.65$, $p<0.001)$ and organisational effectiveness $(r=0.36, p<0.001)$. Further, commitment-based HR practices also significantly and positively correlated with organisational effectiveness $(r=0.53, p<0.001)$.

\section{Hypothesis testing}

Hypothesis 1 predicted an interaction effect of asymmetrical task dependence and commitment-based HR practices on trust climate. As can be seen in Table 2 (fourth column, third model) this interaction was positive and significant $(b=0.25, p<0.05)$. Figure 2 shows this interaction effect graphically, following the procedures of Aiken and West (1991). As expected, asymmetrical task dependence was negatively related to trust climate at low levels of commitment-based HR practices and positively related at high levels. Hence, these results fully supported Hypothesis 1.

Hypothesis 2 predicted a main effect of trust climate on organisational effectiveness. As can be seen in Table 2 (sixth column, second model) this effect was positive and significant $(b=0.21$, $p<0.05)$, and thus supported Hypothesis 2. Hypothesis 3 predicted a moderated-mediation effect, and as can be seen in Table 3, the index of moderated mediation showed that the main effect was positive and the 95 per cent confidence intervals $(95 \% \mathrm{CI})$ did not include zero. These results thus supported Hypothesis 3. To gain greater insight into the moderated-mediation effect the conditional-indirect effects were investigated. As Table 3 shows, the negative effect is relatively stronger than the positive effect (i.e. even at the 25th percentile, the negative effect remains significant, as the $95 \%$ CI does not include zero). Additionally, the positive effect reached significance as well at higher levels (i.e. at the 90th percentile and higher). These findings show that, as expected, the moderated-mediation effect works positively as well as negatively ( $c f$. Figure 2) and thus supports Hypothesis 3. To assess the robustness of our findings, we ran various alternative tests, such a re-analyzing our model in data sets restricted to smaller organisations, excluding the control variables, and assessing alternative moderation models. All tests supported our theorising and main findings (see Supplementary Information, Table 1). 


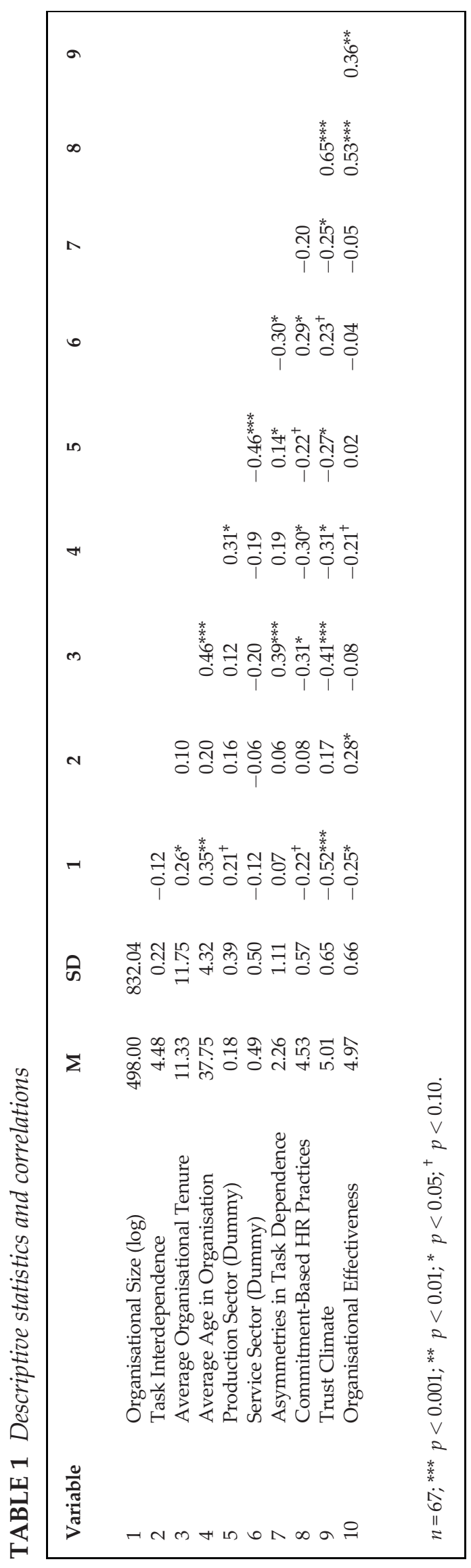


TABLE 2 Main and interaction effects

\begin{tabular}{|c|c|c|c|c|c|}
\hline \multirow[b]{2}{*}{ Variable } & & \multicolumn{2}{|c|}{ Trust Climate } & \multicolumn{2}{|c|}{ Effectiveness } \\
\hline & & B & SE & B & SE \\
\hline \multirow[t]{6}{*}{1 Control Variables } & Organizational Size (log) & $-0.38^{* * *}$ & 0.09 & -0.02 & 0.09 \\
\hline & Task Interdependence & 0.10 & 0.08 & $0.16^{+}$ & 0.08 \\
\hline & Average Organizational Tenure & -0.07 & 0.10 & 0.08 & 0.10 \\
\hline & Average Age in Organization & 0.03 & 0.10 & $-0.17^{\dagger}$ & 0.09 \\
\hline & Production Sector (Dummy) & -0.07 & 0.09 & 0.06 & 0.09 \\
\hline & Service Sector (Dummy) & -0.03 & 0.09 & -0.06 & 0.09 \\
\hline \multirow[t]{3}{*}{2 Main Effects } & Asymmetries in Task Dependence (ATD) & -0.05 & 0.09 & -0.02 & 0.09 \\
\hline & Commitment-Based HR Practices (CBHRP) & $0.65^{* * *}$ & 0.10 & - & - \\
\hline & Trust Climate & - & - & $0.21^{*}$ & 0.10 \\
\hline 3 Interaction & ATD $\times$ CBHRP & $0.25^{*}$ & 0.10 & - & - \\
\hline $\mathrm{R}^{2}$ & & $0.66^{* * *}$ & & $0.24^{*}$ & \\
\hline
\end{tabular}

\section{DISCUSSION}

The starting point of this study was that new advances in one of the key theories on work design (i.e. interdependence theory; Thibaut and Kelley, 1959) had not yet been connected to the organisational level or the HRM literature. Therefore, we sought to investigate whether the recently discovered effects of asymmetrical task dependence on the dyadic, individual and team levels of analysis (e.g. Van der Vegt et al., 2010) would affect organisational-level processes and outcomes. Our moderated-mediation analyses supported all hypotheses, as asymmetrical task dependence was found to be negatively related to trust climate when lower levels of commitment-based HR practices were provided and became increasingly more positive when higher levels of these practices were provided. Below, we discuss the theoretical contributions, the ideas for future research and the strengths and limitations of our study. We conclude with practical implications.

\section{Theoretical implications}

This study advances scientific knowledge in at least three important ways. First, our study advances knowledge on interdependence theory, as most prior studies (regardless of their level of analysis) have overlooked the possibility that asymmetries in task dependence can exist. We advance recent dyadic-level (De Jong et al., 2007), individual-level (De Jong, 2014) and teamlevel studies (Van der Vegt et al., 2010) by showing that asymmetries in task dependence between organisational members can add to, as well as subtract from, the effectiveness of the entire organisation. Hence, our study extends recent advances on interdependence theory, as it takes the investigation to a new level (i.e. organisational level) and is the first to connect this topic to the HR-practice literature.

Our second contribution is the discovery of why our theorising works. More specifically, we revealed that trust climate is a key mechanism which explains why organisational effectiveness is affected when the task interdependencies between organisational members differ. Prior to our study, neither organisational-level theoretical development nor empirical evidence was available to guide practitioners and scholars (Rousseau and Barends, 2011). Moreover, given 
FIGURE 2 Interaction plot

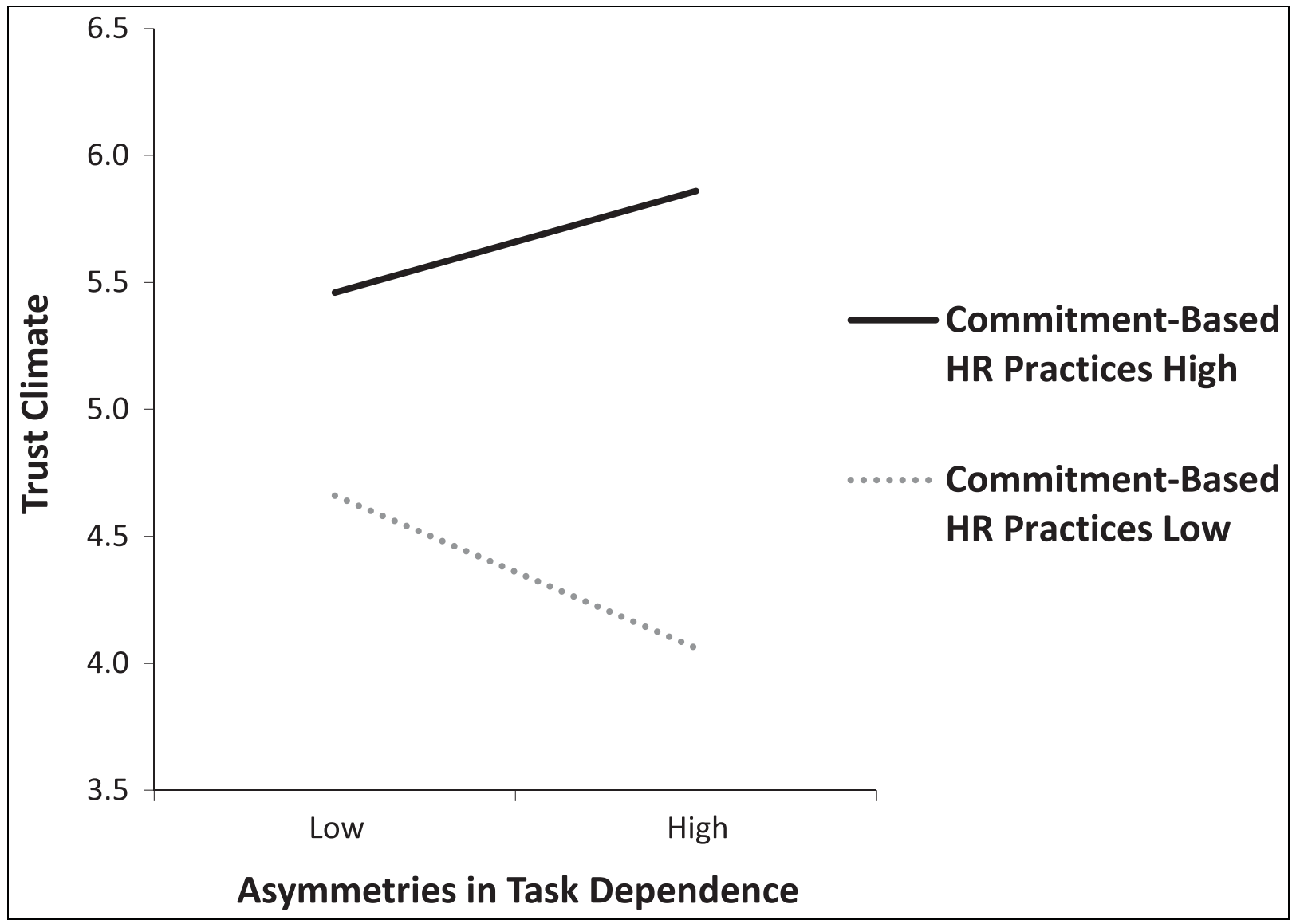

TABLE 3 Moderated-mediation effects

\begin{tabular}{|c|c|c|c|c|}
\hline \multirow{3}{*}{ Asymmetries } & \multicolumn{4}{|c|}{ Direct Effect } \\
\hline & Effect & SE & T-test & Sig. \\
\hline & -0.0175 & 0.0858 & -0.2036 & n.s. \\
\hline & \multicolumn{4}{|c|}{ Conditional Indirect Effects } \\
\hline & Effect & SE (boot) & Lower CI & Upper CI \\
\hline $10^{\text {th }}$ percentile & -0.0733 & 0.0408 & -0.1806 & -0.0155 \\
\hline $25^{\text {th }}$ percentile & -0.0425 & 0.0281 & -0.1180 & -0.0034 \\
\hline $50^{\text {th }}$ percentile & -0.0123 & 0.0194 & -0.0604 & 0.0189 \\
\hline $75^{\text {th }}$ percentile & 0.0128 & 0.0192 & -0.0201 & 0.0595 \\
\hline \multirow[t]{3}{*}{$90^{\text {th }}$ percentile } & 0.0412 & 0.0269 & 0.0000 & 0.1112 \\
\hline & \multicolumn{4}{|c|}{ Index of Moderated Mediation } \\
\hline & Effect & SE (boot) & Lower CI & Upper CI \\
\hline Trust & 0.0531 & 0.0261 & 0.0129 & 0.1195 \\
\hline
\end{tabular}

the limited number of studies on organisational-level trust (Fulmer and Gelfand, 2012), our insights are valuable to that branch of literature as well, as our findings and power-dependence theorising provide a new perspective on the antecedents and consequences of trust climate 
(Huff and Kelley, 2003; Kuenzi and Schminke, 2009). The value of this can be illustrated by, for example, combining our study with Organisational Design (e.g. Nadler and Thusman, 1997; Galbraith, 2014) and HR Value Chain research (e.g. Purcell et al., 2009). Doing so, suggests that one possible reason why prior work- and organisational-design initiatives were not always perceived well by employees is that the design and implementation of these initiatives did not account for the possibility of asymmetries. By overlooking important power-dependence imbalances (Emerson, 1962) employees could have perceived the (re-)design initiative as unrealistic or inappropriate, causing the initiative to achieve less than expected.

Our third contribution is that we revealed how the potentially damaging effect of asymmetries might be circumvented, namely, by offering commitment-based HR practices. This contributes to scholarship by expanding on the recent study of Van der Vegt et al. (2010) which focused on feedback from individual leaders, not the HR practices of the organisation. We extend that recent research by revealing a new moderator at a new level of analysis, and we are the first to connect these advances in interdependence theory directly to the HRM literature. This contributes to the HRM literature, as various scholars (e.g. Huselid and Becker, 2011; Jiang et al., 2012) have recently argued that despite clear progress in unpacking the 'black box', the field of (strategic) HRM still contains few studies that successfully integrate bottom-up theories and scientific developments. Our study provides a concrete example of how this can be done, as we combined the recent advancements in interdependence theory (De Jong et al., 2007) with HR practices research (Collins and Smith, 2006). Additionally, this replies to the call of Searle and Dietz (2012) for more research on the relationship between HRM and trust, and the power-dependence theoretical foundation (e.g. Emerson, 1962) of our study can be used as a theoretical basis for subsequent studies.

For example, prior research on HRM and trust has indicated that particular HR practices, such as reward or training policies, might affect trust (cf. Searle and Dietz, 2012). Our findings expand on such studies in two ways, namely; (a) by indicating that an underlying reason for prior findings might be because some asymmetries or 'vulnerabilities' existed within the studied organisation, even though prior studies did not explicitly investigate this (cf. Rousseau et al., 1998), and (b) that the relationships of specific HR practices with trust might not necessarily arise from the effects of a particular practice, but are perhaps there because they inspire a more collective-orientated focus among workers so that power-dependence relations are less abused (cf. Van der Vegt et al., 2010). Hence, our study highlights the importance of explicitly acknowledging the existence of asymmetries amongst employees within HRM and trust research. This could be particularly relevant for the research on I-deals (e.g. Bal et al., 2012) and a-la-carte HR systems (e.g. Paauwe, 2004) as the idiosyncratic benefits bestowed by such practices might (inadvertently) shape the organisational-level effects of asymmetries.

\section{Future research}

Future research could expand on our study and the prior studies on asymmetries by, for example, assessing a broader range of processes. One option is to use a recent meta-analysis of key mediators in the 'HRM to organisational outcomes relationship', which revealed that human capital, motivation and voluntary turnover were important (Jiang et al., 2012). When researching these mediators, researchers could use multi- and cross-level modelling techniques (Krull and MacKinnon, 2001) as this expands on our 2-2-2 model (called 2-2-2, because the antecedent, mediator and outcome are all analyzed at the organisational level). For example, scholars could assess 1-1-1 models (i.e. all variables at the individual level) and disentangle the underlying individual-level processes that arise from asymmetrical task dependencies while controlling for organisational-level phenomena, such as HR practices, work climates or 
leadership styles (e.g. Combs et al., 2006; Crook et al., 2011). Another option is to explore in greater depth the rational versus the more psychological power mechanisms underlying our model (e.g. Keltner et al., 2003; Fiske and Berdahl, 2007). Such research could investigate whether asymmetries affect lower-level outcomes via individual processes (2-1-1 models) or via organisational processes (2-2-1 models). No study on asymmetries has yet focused explicitly on cross-level effects and, as highlighted in the theoretical contributions, taking up such a perspective might be beneficial to both research on asymmetries as well as research on organisational design (e.g. Galbraith, 2014) and/or the HR Value Chain (Purcell et al., 2009).

Another avenue for future research is to assess the boundary conditions of our theorising. For example, future research could investigate other moderators by drawing on the meta-analysis of Toh et al. (2008) in which five key HR bundles were found, ranging from cost-maximising to commitment-maximising practices. One option is to assess how far along this continuum HR practices have to be to create positive effects from asymmetries. Alternatively, researchers could assess the moderation by transaction-based HR practices (Collins and Smith, 2006). We focused on commitment-based HR practices, as we theorised that they would result in positive effects (Van der Vegt et al., 2010). Yet, based on our underlying power-dependence theorising (Emerson, 1962), future researchers could investigate whether transaction-based practices increase the negative effects of asymmetries by instilling a more individualistic and transactional focus across the organisation (Collins and Smith, 2006). As discussed in the theoretical implication section, a similar argument could be applied to research on idiosyncratic deals (e.g. Bal et al., 2012). To conclude, until our study, no research had connected the new findings on asymmetries in task dependence with the HR-practice literature, and we thus hope our study can be a starting point for more research.

\section{Strengths and limitations}

Naturally, our research design has both strengths and limitations. One limitation might be that we used questionnaire data, which could have introduced common method biases; however, the potential for biases was diminished through our use of four unique sources (Podsakoff et al., 2012). Many recent HRM studies only used single- or dual-source data (cf. Jiang et al., 2012; Bal and Dorenbosch, 2015; Bello-Pintado, 2015), and our use of four sources can thus be viewed as a strength. Another strength is that we focused on interaction effects, because as Evans (1985) has shown, attributing significant two-way interactions to common method biases is very difficult. Last, we also conducted several robustness checks, which all supported our main theorising and findings (see Supporting Information).

In line with recent HRM studies (e.g. Bal and Dorenbosch, 2015; Bello-Pintado, 2015), we chose to measure asymmetry in dependence via the expert opinion of senior professionals with HR responsibility. Additionally, following the HR Value Chain literature (e.g. Purcell et al., 2009), we assessed commitment-based HR practices by assessing employee perceptions of those practices. We think this was the most appropriate way to balance the various considerations into a single research design, yet future scholars could switch these sources and assess employee perceptions of asymmetry in relation to HR-reported HR practices. For example, future researchers could use a more indirect way of assessing asymmetries by collecting data at the dyadic level of analysis (e.g. network or round robin data) and then aggregate this data to the organisational level (Chan, 1998). The underlying theory and logic of our model should apply to these alternative ways of measurement.

Another limitation of this study might be that organisational effectiveness was assessed by asking the top management team members to rate their organisation's effectiveness in 
comparison to that of their competitors. We acknowledge that other more 'objective' measures, such as stock market indices, could also have been valuable, although they have their own strengths and weaknesses (e.g. biases, bubbles, and crashes). However, this was not possible, as most of the organisations in our data set are privately owned and do not have publicly available data ( $c f$. Rogers and Wright, 1998). Other measures, such as total revenues, were likely to differ considerably across the sectors and industries within our data set and, thus, could also not be used. Research has shown that data provided by informed respondents is a valid way to gain insights into organisational effectiveness (Wall et al., 2004; Kunze et al., 2011), and recent HRM studies have used similar methods to assess effectiveness (e.g. Bal and Dorenbosch, 2015; Bello-Pintado, 2015). Therefore, we conclude that it is valid to ask top management members about the effectiveness of the organisations they are leading. Naturally, future studies could replicate our study by using financial or other data.

\section{Practical implications}

Our study has several practical implications, not just for HR professionals but also for others, such as managers, consultants and board members. For instance, our study is relevant for organisations in which diverse interest are not aligned, trust has been violated (cf. Gillespie and Dietz, 2009) and/or work structures are being (re)designed (cf. Nadler and Thusman, 1997; Galbraith, 2014). Practitioners could draw on our study and take a top-down approach by first assessing to what extent asymmetries in task dependence exist across their organisation. If asymmetries are found to be high, one option would be to reduce asymmetries by redesigning the organisational structure ( $c f$. De Jong and Bal, 2014). This might be useful to deal with a (short-term) crisis, as it would prohibit any negative effects from arising. However, as Rousseau et al. (1998) already mentioned, for trust to arise the potential for trust violation needs to exist and by reducing asymmetries the potential for harmful as well as helpful behaviour is reduced; meaning that in organisations with fewer asymmetries, trust might have fewer chances to arise or be repaired (cf. Hurley et al., 2013). Overall, as highlighted in the theoretical implication section, acknowledging that asymmetries could exist can make practical interventions more realistic and therefore more appropriate in the eyes of employees (cf. Purcell et al., 2009).

Another practical value of our study is that it gave more insight into contingency factors (e.g. Delery and Doty, 1996). More specifically, based on our study, practitioners who would like to obtain the possible benefits of asymmetries (and/or cannot intervene in their organisation's structure) could assess whether the level of commitment-based HR practices matches the level of asymmetries. Finding the right match between the organisation's structure and HR practices should pay off in the long term, as it saves managers time in having to fix reoccurring problems arising from poor task design (e.g. by actively and frequently giving group-focused feedback: cf. Van der Vegt et al., 2010) enabling them to devote more time to other tasks. As highlighted in the theoretical implications section, we would also advise practitioners to contemplate that some HR practices, such as a-la-carte HR systems (Paauwe, 2004) or idiosyncratic deals (e.g. Bal et al., 2012) might reduce the positive benefits of asymmetries (or potentially increase their negative effects) as they do not always inspire a commitment to collective outcomes, but might instead instil a competitive individual-focus. Yet, as discussed in the future research section, more research on these topics is necessary.

\section{CONCLUSIONS}

In conclusion, there is increasing evidence that asymmetrical task dependence influences important processes and outcomes. Prior research showed that this ranges from interpersonal 
helping behaviour (De Jong et al., 2007) and individual-level affective reactions (De Jong and Bal, 2014) to team learning and performance (Van der Vegt et al., 2010). Our study showed it also affects the trust climate and effectiveness of organisations. Hence, it is increasingly becoming clear that it is important to acknowledge that asymmetries have potentially positive, as well as negative, effects. Our study supports prior research by showing that providing commitment-based HR practices benefits the organisation as a whole. Yet, it expands on current knowledge by being the first to reveal that this is even more so when asymmetries are high, because then an intra-organisational climate of trust is created wherein organisational effectiveness can truly thrive. Thus, based on our study and the above mentioned prior research, we suggest that practitioners consider asymmetries when maintaining and (re-) developing their organisation and its overall structure (e.g. Nadler and Thusman, 1997; Galbraith, 2014). Overall, our study has increased the arguments in favour of implementing commitment-based HR practices, particularly when there are power-dependence differences within the organisation.

\section{Acknowledgements}

The authors would like to thank the scholars of the IFPM at the University of St. Gallen for their insightful comments on earlier versions of this manuscript and the Energy Factory for help with data collection. This research was supported by a GFF grant from the University of St. Gallen which was awarded to the first author and a mobility grant from the University of Bath awarded to the first and second authors.

\section{Note}

1. In recent years, the debate about what performance is and how it should be measured has intensified, and increasingly scholars (e.g. Bal and Dorenbosch, 2015; Bello-Pintado, 2015) are using novel measures to gain a more holistic and in-depth perspective on the nature of organizational effectiveness. As will be explained in the measurement section, we assessed organizational effectiveness by asking the top management to rate their own company in relation to their competitors on overall performance, business efficiency and increase in market share.

\section{REFERENCES}

Aiken, L.S. and West, S.G. (1991). Multiple Regression: Testing and Interpreting Interactions, London: Sage.

Alge, B.J., Wiethoff, C. and Klein, H.J. (2003). 'When does the medium matter? Knowledge-building experiences and opportunities in decision-making teams'. Organizational Behavior and Human Decision Processes, 91, 26-37.

Bagozzi, R.P. and Heatherton, T.F. (1994). 'A general approach to representing multifaceted personality constructs: application to state self-esteem'. Structural Equation Modeling: A Multidisciplinary Journal, 1: 1, 35-67.

Bal, P.M. and Dorenbosch, L. (2015). 'Age-related differences in the relations between individualised HRM and organisational performance: a large-scale employer survey'. Human Resource Management Journal, 25: 1, 41-61.

Bal, P.M., De Jong, S.B., Jansen, P.G.W. and Bakker, A.B. (2012). 'Motivating employees to work beyond retirement: a multi-level study of the role of I-deals and unit climate'. Journal of Management Studies, 49: 2, 306-331.

Balliet, D. and Van Lange, P.A.M. (2013). 'Trust, conflict, and cooperation: a meta-analysis'. Psychological Bulletin, 139: 5, 1090-1112. 
Barsade, S.G. (2002). 'The ripple effect: emotional contagion and its influence on group behavior'. Administrative Science Quarterly, 47: 4, 644-675.

Bello-Pintado, A. (2015). 'Bundles of HRM practices and performance: empirical evidence from a Latin American context'. Human Resource Management Journal, 25: 3, 311-330.

Bentler, P.M. (2007). 'On tests and indices for evaluating structural models'. Personality and Individual Differences, 42: 5, 825-829.

Bowen, D.E. and Ostroff, C. (2004). 'Understanding HRM-firm performance linkages: the role of the "strength" of the HRM system'. Academy of Management Review, 29: 2, 203-221.

Bunderson, J.S. and Reagans, R.E. (2011). 'Power, status, and learning in organizations'. Organization Science, 22: 5, 1182-1194.

Chan, D. (1998). 'Functional relations among constructs in the same content domain at different levels of analysis: a typology of composition models'. Journal of Applied Psychology, 83: 2, 234-246.

Collins, C.J. and Smith, K.G. (2006). 'Knowledge exchange and combination: the role of human resource practices in the performance of high-technology firms'. Academy of Management Journal, 49: 3, 544-560.

Combs, J., Liu, Y., Hall, A. and Ketchen, D. (2006). ‘How much do high-performance work practices matter? A meta-analysis of their effects on organizational performance'. Personnel Psychology, 59: 3, 501-528.

Crook, T.R., Todd, S.Y., Combs, J.G., Woehr, D.J. and Ketchen, D.J. (2011). 'Does human capital matter? A meta-analysis of the relationship between human capital and firm performance'. Journal of Applied Psychology, 96: 3, 443-456.

De Jong, S.B. and Bal, P.M. (2014). 'How asymmetrical task dependence and task interdependence interact - an individual level study into the effects on affective reactions'. Journal of Managerial Psychology, 29: 8, $1115-1132$.

De Jong, S.B., Van der Vegt, G.S. and Molleman, E. (2007). 'The relationships among asymmetry in task dependence, perceived helping behavior, and trust'. Journal of Applied Psychology, 92: 6, 1625-1637.

Delery, J.E. and Doty, D.H. (1996). 'Modes of theorizing in strategic human resource management: tests of universalistic, contingency, and configurational performance predictions'. Academy of Management Journal, 39: 4, 802-835.

Depret, E. and Fiske, S.T. (1999). 'Perceiving the powerful: intriguing individuals versus threatening groups'. Journal of Experimental Social Psychology, 35: 5, 461-480.

Edwards, J.R. and Lambert, L.S. (2007). 'Methods for integrating moderation and mediation: a general analytical framework'. Psychological Methods, 12: 1, 1-22.

Emerson, R.M. (1962). 'Power-dependence relations'. American Sociological Review, 27: 1, 31-41.

Evans, M.G. (1985). 'A Monte-Carlo study of the effects of correlated method variance in moderated multiple-regression analysis'. Organizational Behavior and Human Decision Processes, 36: 3, 305-323.

Fiske, S.T. and Berdahl, J. (2007). 'Social power', in A.W. Kruglanski and E.T. Higgins (eds), Social Psychology: Handbook of Basic Principles, 2nd edn, New York: Guilford Press.

Fiske, S.T., Harris, L.T. and Cuddy, A.J.C. (2004). 'Why ordinary people torture enemy prisoners'. Science, 306: 5701, 1482-1483.

Fulmer, C.A. and Gelfand, M.J. (2012). 'At what level (and in whom) we trust: trust across multiple organizational levels'. Journal of Management, 38: 4, 1167-1230.

Galbraith, J.R. (2014). Designing Organizations: Strategy, Structure, and Process at the Business Unit and Enterprise Levels, San Francisco, CA: Jossey-Bass.

Gibson, D.E. (2004). 'Role models in career development: new directions for theory and research'. Journal of Vocational Behavior, 65: 1, 134-156.

Giebels, E., De Dreu, C.K.W. and Van de Vliert, E. (2000). 'Interdependence in negotiation: effects of exit options and social motive on distributive and integrative negotiation'. European Journal of Social Psychology, 30: 2, 255-272.

Gillespie, N. and Dietz, G. (2009). 'Trust repair after an organization-level failure'. Academy of Management Review, 34: 1, 127-145.

Gittell, J.H., Seidner, R. and Wimbush, J. (2010). 'A relational model of how high-performance work systems work'. Organization Science, 21: 2, 490-506. 
Hayes, A.F. (2013). Introduction to Mediation, Moderation, and Conditional Process Analysis, New York: The Guilford Press.

Huff, L. and Kelley, L. (2003). 'Levels of organizational trust in individualist versus collectivist societies: a seven-nation study'. Organization Science, 14: 1, 81-90.

Hurley, R.F., Gillespie, N., Ferrin, D.L. and Dietz, G. (2013). ‘Designing trustworthy organizations'. MIT Sloan Management Review, 54: 4, 75-82.

Huselid, M.A. and Becker, B.E. (2011). 'Bridging micro and macro domains: workforce differentiation and strategic human resource management'. Journal of Management, 37: 2, 421-428.

Jiang, K., Lepak, D.P., Hu, J. and Baer, J.C. (2012). ‘How does human resource management influence organizational outcomes? A meta-analytic investigation of mediating mechanisms'. Academy of Management Journal, 55: 6, 1264-1294.

Keltner, D., Gruenfeld, D.H. and Anderson, C. (2003). ‘Power, approach, and inhibition'. Psychological Review, 110: 2, 265-284.

Krull, J.L. and MacKinnon, D.P. (2001). 'Multilevel modelling of individual and group level mediated effects'. Multivariate Behavioral Research, 36: 2, 249-277.

Kuenzi, M. and Schminke, M. (2009). 'Assembling fragments into a lens: a review, critique, and proposed research agenda for the organizational work climate literature'. Journal of Management, 35: 3, 634-717.

Kunze, F., Boehm, S.A. and Bruch, H. (2011). 'Age diversity, age discrimination climate and performance consequences: a cross organizational study'. Journal of Organizational Behavior, 32: 2, 264-290.

Lewin, K. (1948). Resolving Social Conflicts, New York: Harper.

McEvily, B., Perrone, V. and Zaheer, A. (2003). 'Trust as an organizing principle'. Organization Science, 14: 1, 91-103.

Monks, K., Kelly, G., Conway, E., Flood, P., Truss, K. and Hannon, E. (2013). ‘Understanding how HR systems work: the role of HR philosophy and HR processes'. Human Resource Management Journal, 23: 4, 379-395.

Montes, S. and Irving, P. (2008). 'Disentangling the effects of promised and delivered inducements: relational and transactional contract elements and the mediating role of trust'. Journal of Applied Psychology, 93: 6, 1367-1381.

Nadler, D.A. and Thusman, M. (1997). Competing by Design: The Power of Organizational Architecture, Oxford: Oxford University Press.

Paauwe, J. (2004). HRM and Performance: Achieving Long-Term Viability, Oxford: Oxford University Press.

Podsakoff, P.M., MacKenzie, S.B. and Podsakoff, N.P. (2012). 'Sources of method bias in social science research and recommendations on how to control it'. Annual Review of Psychology, 63, 539-569.

Purcell, J., Kinnie, N., Swart, J., Rayton, B. and Hutchinson, S. (2009). People Management and Performance, London: Routledge.

Ragins, B.R., Cotton, J.L. and Miller, J.S. (2000). 'Marginal mentoring: the effects of type of mentor, quality of relationship, and program design on work and career attitudes'. Academy of Management Journal, 43: 6, 1177-1194.

Rogers, E.W. and Wright, P.M. (1998). 'Measuring organizational performance in strategic human resource management: problems, prospects, and performance information markets'. Human Resource Management Review, 8: 3, 311-331.

Rousseau, D.M. and Barends, E.G.R. (2011). 'Becoming an evidence-based HR practitioner'. Human Resource Management Journal, 21: 3, 221-235.

Rousseau, D.M., Sitkin, S.B., Burt, R.S. and Camerer, C. (1998). 'Not so different after all: a cross-discipline view of trust'. Academy of Management Review, 23: 3, 393-404.

Saavedra, R., Earley, P.C. and Vandyne, L. (1993). 'Complex interdependence in task-performing groups'. Journal of Applied Psychology, 78: 1, 61-72.

Sanders, K., Shipton, H. and Gomes, J.F.S. (2014). 'Guest editors' introduction: is the HRM process important? Past, current, and future challenges'. Human Resource Management, 53: 4, 489-503.

Searle, R.H. and Dietz, G. (2012). 'Trust and HRM: current insights and future directions'. Human Resource Management Journal, 22: 4, 333-342. 
Sheehan, C., De Cieri, H., Cooper, B. and Brooks, R. (2014). 'Exploring the power dimensions of the human resource function'. Human Resource Management Journal, 24: 2, 193-210.

Shockley-Zalabak, P., Ellis, K. and Winograd, G. (2000). ‘Organizational trust: what it means, why it matters'. Organization Development Journal, 18: 4, 35-48.

Thibaut, J.W. and Kelley, H.H. (1959). The Social Psychology of Groups, New York: Wiley.

Thompson, J.D. (1967). Organizations in Action, New York: McGraw-Hill.

Tjosvold, D., Poon, M. and Yu, Z.Y. (2005). 'Team effectiveness in China: cooperative conflict for relationship building'. Human Relations, 58: 3, 341-367.

Toh, S.M., Morgeson, F.P. and Campion, M.A. (2008). 'Human resource configurations: investigating fit with the organizational context'. Journal of Applied Psychology, 93: 4, 864-882.

Van der Vegt, G.S., Van de Vliert, E. and Oosterhof, A. (2003). 'Informational dissimilarity and organizational citizenship behavior: the role of intrateam interdependence and team identification'. Academy of Management Journal, 46: 6, 715-727.

Van der Vegt, G.S., Emans, B.J.M. and Van de Vliert, E. (2005). The congruence hypothesis of intrateam interdependence in organizations: some recent findings and their implications for theory and practice. In C. Schriesheim and L. Neider (eds), Research in Management: Understanding Teams, Charlotte, NC: Information Age Publishing, pp. 111-131.

Van der Vegt, G.S., De Jong, S.B., Bunderson, J.S. and Molleman, E. (2010). 'Power asymmetry and learning in teams: the moderating role of performance feedback'. Organization Science, 21: 2, 347-361.

Wageman, R. and Baker, G. (1997). 'Incentives and cooperation: the joint effects of task and reward interdependence on group performance'. Journal of Organizational Behavior, 18: 2, 139-158.

Wall, T.D., Michie, J., Patterson, M., Wood, S.J., Sheehan, M., Clegg, C.W. and West, M. (2004). ‘On the validity of subjective measures of company performance'. Personnel Psychology, 57: 1, 95-118.

Weiss, H.M. and Cropanzano, R. (1996). 'Affective events theory: a theoretical discussion of the structure, causes, and consequences of affective experiences at work'. In B.M. Staw and L.L. Cummings (eds), Research in Organizational Behavior, vol. 18, Greenwich, CT: JAI Press, pp. 1-74.

Wieselquist, J., Rusbult, C.E., Foster, C.A. and Agnew, C.R. (1999). 'Commitment, pro-relationship behavior, and trust in close relationships'. Journal of Personality and Social Psychology, 77: 5, 942-966.

Williams, L.J. and O'Boyle, E.H. (2008). 'Measurement models for linking latent variables and indicators: a review of human resource management research using parcels'. Human Resource Management Review, 18: 4, 233-242.

Woodrow, C. and Guest, D.E. (2014). 'When good HR gets bad results: exploring the challenge of HR implementation in the case of workplace bullying'. Human Resource Management Journal, 24: 1, $38-56$. 